Review Article

\title{
Infant and Young Child Feeding
}

\author{
NITA BHANDARI* and RANADIP CHOWDHURY \\ Centre for Health Research and Development, Society for Applied Studies, 45, Kalu Sarai, New Delhi, \\ India
}

(Received on 02 June 2016; Accepted on 15 June 2016)

\begin{abstract}
Nutrition during the entire life cycle is a key driver of growth and development. Foetal life and early childhood years are the phases when growth and development are maximum, coinciding with a period of great vulnerability to sub-optimal environment, with early as well as long-term consequences. It is in this context that optimal feeding of infants and young children is critically important. This chapter describes the recommended practices of breast-feeding, and the recommendations for vulnerable subgroups such as low birth weight and HIV infected infants. It also emphasizes on strong lactation support for mothers and describes ways for promoting optimal practices. Feeding of complementary foods after 6 months of age, the guiding principles for complementary feeding of the breast-fed children and the nutritional requirements from complementary feeding are also covered. As non-dietary determinants such as water, sanitation, hygiene, and other factors influence nutritional status of children, integrated interventions are likely to have a greater impact on stunting, rather than individual components alone.
\end{abstract}

Keywords: Breast-Feeding; Complementary Feeding

\section{Introduction}

Nutrition during the life cycle is a key driver of growth and development. Foetal life and early childhood years are the phases when growth and development are maximum, coinciding with a period of great vulnerability to sub-optimal environment with early, as well as, long-term consequences. It is in this context that optimal feeding of infants and young children is critically important. It bears recognition that mother's nutrition is also critical to foetal growth and development and effective nurturing of the young infant. There are clearly non-dietary determinants such as water, sanitation, hygiene and other factors that influence the nutritional status of the child, as well as, infant feeding behaviours. Progress in children's nutrition requires effective integration and convergence in design and program delivery for future progress.

\section{How Detrimental is Early Life Poor Nutrition from a Long-term Perspective?}

Impaired growth and development at birth and during the initial 2-3 years of life and anthropometry around

\footnotetext{
*Author for Correspondence: E-mail: nita.bhandari@sas.org.in
}

2 years of age correlate significantly with adult educational and economic attainment, as well as health, particularly; the risk of chronic disease (Victora et al., 2008). Recognising the importance of nutrition throughout the life cycle, this chapter focuses on infant and child feeding. In the first two years of life, impaired growth is easier to prevent and correct through catchup during this period; the latter is relatively more difficult to accomplish later in childhood. The growing brain at this age is also vulnerable to nutrition related insults with potential long-term concerns (Georgieff, 2007).

\section{Are We Making Progress and At What Rate?}

Infant and child feeding is sub-optimal in large parts of the world and this is reflected by the slow progress in decline of wasting and stunting in many countries, as well as the growing trend towards obesity in developed and indeed emerging in many developing countries. The decline in different nutritional indicators in under-threes in two national surveys is shown in Fig. 1 (Sachdev, 2012). A recent rapid survey in 
children aged 0 to 59 months in 28 states shows improvements in indicators, but the rates are still high with overall stunting [height-for-age (HAZ) below -2 standard deviation (SD)] at 38\%, wasting [weightfor-height (WHZ) below -2 SD] at $15.1 \%$ and underweight [weight-for-age (WAZ) below -2 SD] at 29.4\% (Government of India, 2015).

\section{Breast-Feeding}

\section{Recommended Practices}

Research has conclusively demonstrated the importance of optimal breast-feeding practices for survival, growth and development in the first two years of life. The World Health Organisation (WHO) and United Nations Children's Fund (UNICEF) global recommendations are early initiation of breast-feeding within one hour of birth, exclusive breast-feeding (EBF) for first 6 months i.e. 180 days and continued breast-feeding up to 2 years of age or beyond (WHO, 2009).

\section{Early Initiation of Breast-feeding}

Early initiation of breast-feeding means initiation of breast-feeding within one hour of birth. A systematic review suggests that breast-feeding initiation within 24 hours of birth is associated with $44 \%$ reduction in all-cause neonatal mortality (Debes et al., 2013). A recent pooled analysis from three large randomised trials reported that initiation of breast-feeding in the first one hour of life leads to large reduction in neonatal mortality; $29 \%$ when compared to those who initiated at 2 to 23 hours and $44 \%$ when compared to those initiating at 24 to 96 hours (Neovita Study Group, 2016).

\section{Exclusive Breast-feeding}

EBF means that an infant receives only breast milk from his or her mother or a wet-nurse, or expressed breast milk, and no other liquids or solids, not even water, except oral rehydration solution, drops or syrups consisting of vitamins, minerals and medicines (WHO, 2008).

Breast-feeding practices in major states of India from two national surveys are shown in Table 1 (International Institute for Population Sciences and Macro International, 2007; International Institute for Population Sciences, 2016).

Non-breast-fed infants are more likely to die, the risk being 14 times higher compared to infants who are exclusively breast-fed from 0 to 5 months (Sankar et al., 2015). The risk of death from infections in partially breast-fed infants $0-5$ months of age was 4.56 times the risk for exclusively breast-fed children; this increased to 8.66 times for those who did not receive any breast milk (Sankar et al., 2015). EBF reduces incidence of diarrhoea and hospitalizations for diarrhoea and lower respiratory tract infections in the first 2 years of life year by $32 \%$ (Horta and Victora, 2013). EBF for first 6 months shows $43 \%$ reduction in acute otitis media in the first 2 years of life (Bowatte et al., 2015). EBF for more than 3 to 4 months is associated with $26 \%$ reduced risk of eczema in children aged less than 2 years (Lodge et al., 2015).

Breast milk contains many anti-infective factors that explain these protective effects. These are secretary IgA, lactoferrin, lysozyme, alphalactalbumin and lactadherin (Goldman, 2007). Breast milk contains a wider variety of sugars than other mammalian milks; these promote healthy gut

Table 1: Trends in breast-feeding practices in major states of India

\begin{tabular}{|c|c|c|c|c|c|c|c|c|c|c|}
\hline & \multicolumn{2}{|c|}{ Haryana } & \multicolumn{2}{|c|}{ Tamil Nadu } & \multicolumn{2}{|c|}{ Bihar } & \multicolumn{2}{|c|}{ Maharashtra } & \multicolumn{2}{|c|}{ Madhya Pradesh } \\
\hline & NFHS 4 & NFHS3 & NFHS4 & NFHS3 & NFHS4 & NFHS3 & NFHS4 & NFHS3 & NFHS4 & NFHS3 \\
\hline $\begin{array}{l}\text { Children under age } 3 \text { years breast- } \\
\text { fed within } 1 \text { hour of } \text { birth }^{\mathrm{a}}(\%)\end{array}$ & 42.4 & 22.3 & 54.7 & 55.2 & 34.9 & 4 & 57.5 & 51.8 & 34.5 & 14.9 \\
\hline $\begin{array}{l}\text { Children under age } 6 \text { months } \\
\text { exclusively breast-fed }(\%)\end{array}$ & 50.3 & 16.9 & 48.3 & 34.1 & 53.5 & 28 & 56.6 & 53 & 58.2 & 21.6 \\
\hline
\end{tabular}


colonization (Victora et al., 2016). Human milk oligosaccharides also block adhesion of microbial pathogens to epithelial surfaces; this is critical for repair during enteric infections (Jantscher-Krenn and Bode, 2012).

EBF for the first 6 months of life meets the energy and nutrient needs of the majority of infants and no other foods or fluids are necessary (WHO, 2002a). As breast milk itself is $88 \%$ water, it is enough to satisfy a baby's thirst and exclusively breast-fed babies do not need additional water during the first 6 months of life even in hot and humid weather (Linkages/AED, 2002). Fluids given to breast-fed babies displace breast milk (Sachdev et al., 1991). In India, however, water, tea, honey and a range of other fluids are commonly given to infants starting soon after birth and this practice is associated with an increased risk of diarrhoea (Upadhyay et al., 2012; Hajeebhoy et al., 2014).

\section{Continued Breast-feeding}

A longer period of breast-feeding is associated with $26 \%$ reduction of childhood and adolescent overweight or obesity and $35 \%$ reduction in incidence of type-2 diabetes (Horta et al., 2015a). Breast-feeding is associated with higher performance in intelligence tests in children and adolescents (Horta et al., 2015b). The risk of long-term diseases that have an immunological basis is increased in artificially-fed children. These include type 1 diabetes (SadauskaiteKuehne et al., 2004), celiac disease (Akobeng et al., 2006), ulcerative colitis and Crohn disease (Klement et al., 2004). Breast-feeding is associated with a $19 \%$ reduction in incidence of childhood leukaemia (Amitay and Keinan-Boker, 2015).

There is an increasing tendency to shorten duration of breast-feeding from the recommended levels of up to 2 years of age. Breast milk helps to improve dietary quality in settings where complementary feeds are largely cereal-based, and during the second year of life, any amount of breastfeeding is protective against infections such as shigellosis (Clemens et al., 1986, Lindsay et al., 2015).

\section{Breast-feeding and Maternal Morbidity}

Breast-feeding is associated with $26 \%$ reduced risk of breast cancer and $37 \%$ reduced risk of ovarian carcinoma. Breast-feeding for more than 12 months provides additional protection against both breast and ovarian cancer (Chowdhury et al., 2015). Breastfeeding is associated with $32 \%$ lower risk of type 2 diabetes (Aune et al., 2014). EBF and predominant breast-feeding are associated with $23 \%$ higher probability of amenorrhea at 6 months (Chowdhury et al., 2015). A shorter duration of breast-feeding is associated with higher risk of postpartum depression (Dias and Figueiredo, 2015).

\section{Recommendations for Low Birth Weight Infants}

Low birth weight (LBW), defined as birth weight less than $2500 \mathrm{~g}$, can be a consequence of pre-term birth (defined as birth before 37 completed weeks of gestation) or small for gestational age (SGA), defined as weight for gestation. LBW directly or indirectly may contribute up to $60 \%$ to $80 \%$ of all neonatal deaths (Lawn et al., 2005). Infant mortality rates in countries can be substantially reduced by improving the care of this highly vulnerable group. The recommendations on optimal feeding of LBW and very low birth weight (VLBW; birth weight between 1 and $1.5 \mathrm{~kg}$ ) infants are that they should be fed mother's own milk, and donor human milk for those who cannot be fed mother's own milk. LBW infants should be exclusively breast-fed until 6 months of age. Infant formula should be fed only if mother's or donor milk is not available. VLBW infants who cannot be fed mother's own milk or donor human milk should be given preterm infant formula if they fail to gain weight despite adequate feeding with standard infant formula. Additionally, VLBW infants should be given vitamin D supplements (until 6 months of age), calcium (first month of life), phosphorus (first month of life) and iron (from 2 weeks to 6 months of age) (WHO, 2011a).

\section{HIV and Infant Feeding}

Mothers known to be HIV-infected (and whose infants are HIV uninfected or of unknown HIV status) should exclusively breast-feed their infants for the first 6 months of life, introducing appropriate complementary foods thereafter, and continue breastfeeding for the first 12 months of life. In HIV-infected infants, mothers are strongly encouraged to follow the recommendations for the general population. When mothers known to be HIV-infected decide to 
stop breast-feeding at any time, infants should be provided with safe and adequate replacement feeds (WHO, 2010).

\section{Support for Breast-feeding Mothers}

Lactation support is important for mothers to prevent and manage lactation failure. Factors that lead to lactational failure may be delayed initiation, infrequent breast-feeding, no night feeding, problems in positioning and attachment or use of bottles and pacifiers. Mother's lack of confidence, depression, anxiety and stress, sore nipples, breast abscess, maternal alcohol and smoking are important maternal contributing factors. Promoting lactational support services is particularly important in India where LBW and prematurity are common (Periera et al., 2015).

\section{Promotion of Breast-feeding}

Countries have adopted several measures to protect and promote breast-feeding on a universal basis, for all socio-economic classes. These include; legislation, promotion of essential newborn care through community health workers, nurses and physicians, communication and advertising, maternity leave for working mothers and crèches at the workplace. The challenge now is to accelerate universal achievement of breast-feeding indicators across India.

Promotion of breast-feeding using a combination of settings i.e. at home, facility and community have shown higher improvements in breast-feeding rates. Greatest improvements in early initiation of breastfeeding, EBF and continued breast-feeding rates, were seen when counselling or education was provided concurrently in homes and community, health systems and community, and health systems and home settings. The baby friendly hospital support at the health system was the most effective intervention to improve rates of any breast-feeding (Sinha et al., 2015).

The available opportunities provided by increasing institutional deliveries, home visitation by Accredited Social Health Activist (ASHA) workers to promote essential newborn care, community mobilization and mass communication approaches must be utilized better in the country to enhance quality and coverage of optimal breast-feeding as defined above.

\section{Complementary Feeding}

Complementary feeding refers to introduction of other foods and liquids, when nutritional requirements of an infant cannot be met with breast milk alone. WHO and UNICEF recommend nutritionally adequate and safe complementary feeding starting after 6 months of age with continued breast-feeding up to 2 years of age or beyond (WHO, 2009).

The high prevalence of malnutrition in countries like India is largely driven by inappropriate complementary feeding practices. Premature cessation of breast-feeding and introduction of complementary foods before 6 months leads to increased exposure to pathogens especially in environments with suboptimal water supply, sanitation and hygiene practices. Inappropriate complementary feeding practices include not starting complementary foods at 6 months of age, inadequate macro and micronutrient intakes from staple-based complementary foods especially, in vegetarian populations and failure to increase the amounts fed at each meal and frequency of feeding with increasing age. These practices have proven to be difficult to change rapidly in most parts of India, demanding new and improved strategies.

The guiding principles for complementary feeding of the breast-fed child are given below.

1. Practise exclusive breast-feeding from birth to 6 months of age, and introduce complementary foods after 6 months of age (180 days) while continuing to breast-feed.

2. Continue frequent, on-demand breast-feeding until 2 years of age or beyond.

3. Practise responsive feeding, applying the principles of psychosocial care.

4. Practise good hygiene and proper food handling.

5. Start at 6 months of age with small amounts of food and increase the quantity as the child gets older, while maintaining frequent breast-feeding.

6. Gradually increase food consistency and variety as the infant grows older, adapting to the infant's requirements and abilities.

7. Increase the number of times that the child is 
fed complementary foods as the child gets older.

8. Feed a variety of nutrient-rich foods to ensure that all nutrient needs are met.

9. Use fortified complementary foods or vitaminmineral supplements for the infant, as needed

10. Increase fluid intake during illness, including more frequent breast-feeding, and encourage the child to eat soft, favourite foods. After illness, give food more often than usual and encourage the child to eat more.

(Source: WHO/PAHO, 2001)

Complementary feeding should be timely i.e. all infants should be given foods in addition to breast milk from 6 months onwards. It should be adequate, meaning that complementary feeding should be given in amounts, frequency, and consistency, using a variety of foods to cover the nutritional need of the growing child while maintaining breast-feeding.

The complementary feeding practices in major states of India in two national surveys (conducted in Years 2005-2006 and 2015-2016) are shown in Table 2 (International Institute for Population Sciences and Macro International, 2007; International Institute for Population Sciences, 2016). The decline in the percentage of children age 6-8 months receiving solid or semi-solid foods and breast milk between the two surveys is difficult to explain; some reasons may be changes in the ascertainment methods, an increase in the food inflation rate or other factors.

Responsive feeding is used to describe feeding methods that apply the principles of psycho-social care. In many communities in India, caregivers do not offer encouragement and young children are left to feed themselves. In such settings, a more active approach in which mothers feed the child recognizing signs of hunger and satiety improve dietary intakes. Foods should be prepared and given in a safe manner to minimize the risk of contamination with pathogens. They should be given in a way that the consistency is appropriate, i.e., texture is appropriate for age of the child. The quality, frequency and amount of food required between 6 months and 23 months of age are summarized in Table 3.

\section{Feeding Non-breast-fed Children 6-23 Months of Age}

Non-breast-fed children need extra food to compensate for not receiving breast milk, which can provide a half of their energy needs from 6 to 12 months and a third between 12 to 23 months (WHO, 2005). These children need to be fed a large quantity of foods containing high quality nutrients that would otherwise be covered by breast milk. This can be achieved by giving extra meals, meals of greater

Table 2: Trends in Complementary Feeding Practices in Major States of India

\begin{tabular}{|c|c|c|c|c|c|c|c|c|c|c|}
\hline & \multicolumn{2}{|c|}{ Haryana } & \multicolumn{2}{|c|}{ Tamil Nadu } & \multicolumn{2}{|c|}{ Bihar } & \multicolumn{2}{|c|}{ Maharashtra } & \multicolumn{2}{|c|}{ Madhya Pradesh } \\
\hline & NFHS 4 & NFHS3 & NFHS4 & NFHS3 & NFHS4 & NFHS3 & NFHS4 & NFHS3 & NFHS4 & NFHS3 \\
\hline $\begin{array}{l}\text { Children age } 6-8 \text { months receiving } \\
\text { solid or semi-solid food and breast } \\
\text { milk }^{\mathrm{a}}(\%)\end{array}$ & 35.9 & 42.6 & 67.5 & 81.2 & 30.7 & 54.5 & 43.3 & 45.5 & 38.1 & 46 \\
\hline $\begin{array}{l}\text { Breast-feeding children age } 6-23 \\
\text { months receiving an adequate diet }{ }^{\mathrm{a}, \mathrm{b}}(\%)\end{array}$ & 7 & NA & 21.4 & NA & 7.3 & NA & 5.3 & NA & 6.9 & NA \\
\hline $\begin{array}{l}\text { Non-breast-feeding children age } 6-23 \\
\text { months receiving an adequate } \operatorname{diet}^{\mathrm{a}, \mathrm{b}}(\%)\end{array}$ & 10 & NA & 47.1 & NA & 9.2 & NA & 12.2 & NA & 4.8 & NA \\
\hline $\begin{array}{l}\text { Total children age } 6-23 \text { months receiving } \\
\text { an adequate diet } \mathrm{a}^{\mathrm{a}, \mathrm{b}}(\%)\end{array}$ & g 7.5 & NA & 30.7 & NA & 7.5 & NA & 6.5 & NA & 6.6 & NA \\
\hline
\end{tabular}

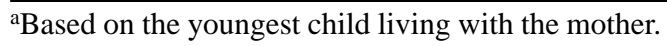

${ }^{b}$ Breast-fed children receiving 4 or more food groups and a minimum meal frequency, non-breast-fed children fed with a minimum of 3 Infant and Young Child Feeding Practices (fed with other milk or milk products at least twice a day, a minimum meal frequency that is receiving solid or semi-solid food at least twice a day for breast-fed infants 6-8 months and at least three times a day for breast-fed children 9-23 months, and solid or semi-solid foods from at least four food groups not including the milk or milk products food group) Source: International Institute for Population Sciences (2016) NFHS 4 fact sheets for key indicators based on final data, http:// rchiips.org/nfhs/factsheet_nfhs-4.shtml 
Table 3: Practical guidance on the quality, frequency and amount of food to offer children 6-23 months of age who are breastfed on demand

\begin{tabular}{|c|c|c|c|c|}
\hline Age & $\begin{array}{l}\text { Energy needed/day } \\
\text { in addition to breast } \\
\text { milk }\end{array}$ & Texture & Frequency & $\begin{array}{l}\text { Amount of food an average child will } \\
\text { usually eat at each meal assuming } \\
\text { energy density of } 0.8 \text { to } 1.0 \mathrm{kcal} / \mathrm{g} *\end{array}$ \\
\hline $6-8$ months & $200 \mathrm{kcal} /$ day & $\begin{array}{l}\text { Start with thick porridge, } \\
\text { well mashed foods } \\
\text { Continue with mashed } \\
\text { may be offered }\end{array}$ & $\begin{array}{l}\text { 2-3 meals per day } \\
\text { Depending on the child's } \\
\text { appetite, } 1-2 \text { snacks } \\
\text { family foods }\end{array}$ & $\begin{array}{l}\text { Start with 2-3 tablespoonfuls per feed, } \\
\text { increasing gradually to } 1 / 2 \text { of a } 250 \mathrm{ml} \\
\text { cup }\end{array}$ \\
\hline 9-11 months & $300 \mathrm{kcal} /$ day & $\begin{array}{l}\text { Finely chopped or mashed } \\
\text { foods, and foods that baby } \\
\text { can pick up }\end{array}$ & $\begin{array}{l}\text { 3-4 meals per day } \\
\text { Depending on the child's } \\
\text { appetite, } 1-2 \text { snacks } \\
\text { may be offered }\end{array}$ & $1 / 2$ of a $250 \mathrm{ml} \mathrm{cup} /$ bowl \\
\hline $12-23$ months & $550 \mathrm{kcal} /$ day & $\begin{array}{l}\text { Family foods, chopped } \\
\text { or mashed if necessary }\end{array}$ & $\begin{array}{l}3-4 \text { meals per day } \\
\text { Depending on the child's } \\
\text { appetite, } 1-2 \text { snacks } \\
\text { may be offered }\end{array}$ & $3 / 4$ to full $250 \mathrm{ml} \mathrm{cup} / \mathrm{bowl}$ \\
\hline
\end{tabular}

*If baby is not breast-fed, give in addition: 1-2 cups of milk per day, and 1-2 extra meals per day (WHO, 2005).

Source: WHO, 2009

energy density, and larger quantity of foods of animal origin or nutrient supplements if foods of animal origin are not available (WHO, 2005).

\section{Requirements from Complementary Feeding in Early Childhood}

After 12 months of age, complementary food should provide nearly $60 \%$ energy, $40 \%$ protein, and over $50 \%$ iron and $20 \%$ vitamin A of the total daily requirement. The large gap in breast milk for iron is noteworthy, and this explains the common occurrence of anaemia in early years of life. Complementary foods must therefore, provide adequate iron by fortification or by use of animal source foods. Absorption of pulses can be improved by providing vitamin $\mathrm{C}$ but some amount of animal source food or fortified food or supplement is needed by adopting one or more of several possible approaches. For infants and young children, fortification of staple foods such as wheat flour and rice is unlikely to close the "gap" in micronutrient intake from complementary foods, particularly for iron and zinc. This is because children under 2 years of age consume a small amount of complementary food. To meet their iron and zinc needs, the staple foods will need to be fortified at higher levels, so that the recommended intakes could be achieved with daily intake. For this reason, specialized products targeted at infants and young children have been developed. Fortified products for complementary feeding have been categorized into three general types: a) fortified blended foods, b) micronutrient powders, and c) complementary food supplements (Young Child Nutrition Working Group, 2009). Each of these options has advantages and disadvantages, so the best choice depends on the context (Dewey and Vitta, 2013). The provision and/ or marketing of fortified products should be coupled with educational messages on breast-feeding and complementary feeding.

\section{Dietary Diversity}

The standard of complementary feeding depends on amount and frequency appropriate for age, food diversity through staples, foods from animal sources, dairy products, pulses and through consumption of a range of coloured fruits and vegetables, and fats and oils. Dietary diversity is integral for balanced nutrition. Lack of diversity is common in Indian children between 6 months to 3 years of age (Bentley et al., 2015). All animal foods, including eggs and fish are rich in high quality proteins, iron, zinc and most vitamins including vitamin B12; dairy products in protein, energy, minerals, particularly calcium and vitamins; pulses in protein, and some iron; coloured (especially orange, red and yellow) fruits and vegetables in $\beta$-carotene (provitamin A), and vitamin 
C. Green leafy vegetables are rich source of most micronutrients- vitamins and minerals. Vitamin C-rich fruits like gooseberries (Amla), guava and citrus improve iron absorption from plant foods. Energy density of complementary food should be at least $0.8 \mathrm{kcal} / \mathrm{g}$.

Fats and oils provide required energy density and improve palatability of complementary foods.

Overall, good complementary feeding recommenda-tions in a setting must yield a diet, rich in energy, iron, zinc, calcium, vitamins and folate. Staples such as; cereals, roots and starchy foods provide the basic ingredients of complementary foods. Care providers must be taught the skills of adding other foods to staple foods in a context-specific manner, to achieve quality and balance in complementary feeding.

\section{Developing Feeding Recommendations for a Region}

A protocol for adapting feeding recommendations is available, that enables program managers to identify locally available, energy-dense culturally acceptable foods, common feeding problems and developing a draft list of feeding recommendations for the area (WHO, 2002b). Household trials are used to test the improved feeding recommendation (WHO, 2002b). Post testing, a final list of recommendations for the area are developed and these are filled in a box that has recommendations for different age categories and specifies the frequency and amounts of the locally acceptable foods to be fed at different ages (WHO, 2002b).

Opti-food is a linear programming software application that allows public health professionals to identify the nutrients children obtain from their local diets and to formulate and test population-specific food-based recommendations to meet their special needs. Optimization analyses help specify the lowest cost combination of local foods that will meet or come as close as possible to satisfy the nutrient needs of the target group (http://www.fantaproject.org/tools/ optifood).

\section{WHO Recommendations for Micronutrients}

In settings, where prevalence of anaemia in children under 2 years or under 5 years of age is $20 \%$ or higher, home fortification of foods with multiple micronutrient powders is recommended to improve iron status and reduce anaemia among infants and children 6-23 months of age (WHO, 2011b).

Others support food-based approaches, including fortification as being more appropriate. In the local context, it is important to develop clear guidelines based on evidence and policies.

\section{Rehabilitation of Severe Acute Malnourished (SAM) Children}

This sub-group of children is a medical emergency as they require medical attention in addition to dietary rehabilitation for care. In India, about 1-5\% children may suffer from SAM [WFH Z score below -3 SD], which is associated with 12 -fold higher risk of mortality than having a normal anthropometric status; the risk increases to 20 -fold with very severe wasting (WHZ below -4 SD) (Olofin et al., 2013). The detailed management and rehabilitation strategy of this vulnerable sub-group of children has been described elsewhere, in another article of this special issue.

\section{Integrated Interventions in the 1000-day Window}

Growth in the first two years of life is driven largely by early infant feeding practices and the absence of significant morbidity. Exclusive and continued breastfeeding, energy and nutrient rich complementary foods, responsive feeding practices, safe water and sanitation prevent infectious diseases, such as diarrhoea; water, sanitation and hygiene practices are also associated with reduced risk of enteropathies and gut inflammation that may significantly impair growth potential. The concept of the 'first 1000 days' between conception and 2 years of age highlights the critical window of opportunity to deliver interventions that will improve the survival and health of children. Integrated interventions that combine nutrition, infection control and care for mothers and children are likely to have a larger impact on stunting, than any of these components alone.

The nutritional state of women in the periconception period influences early cell division, and the epigenetic state of infants at birth strongly predicts body composition in later childhood. These observations lead to a concept of integrated interventions as a continuum for "1000 days plus" starting in pre-conception and continuing through 


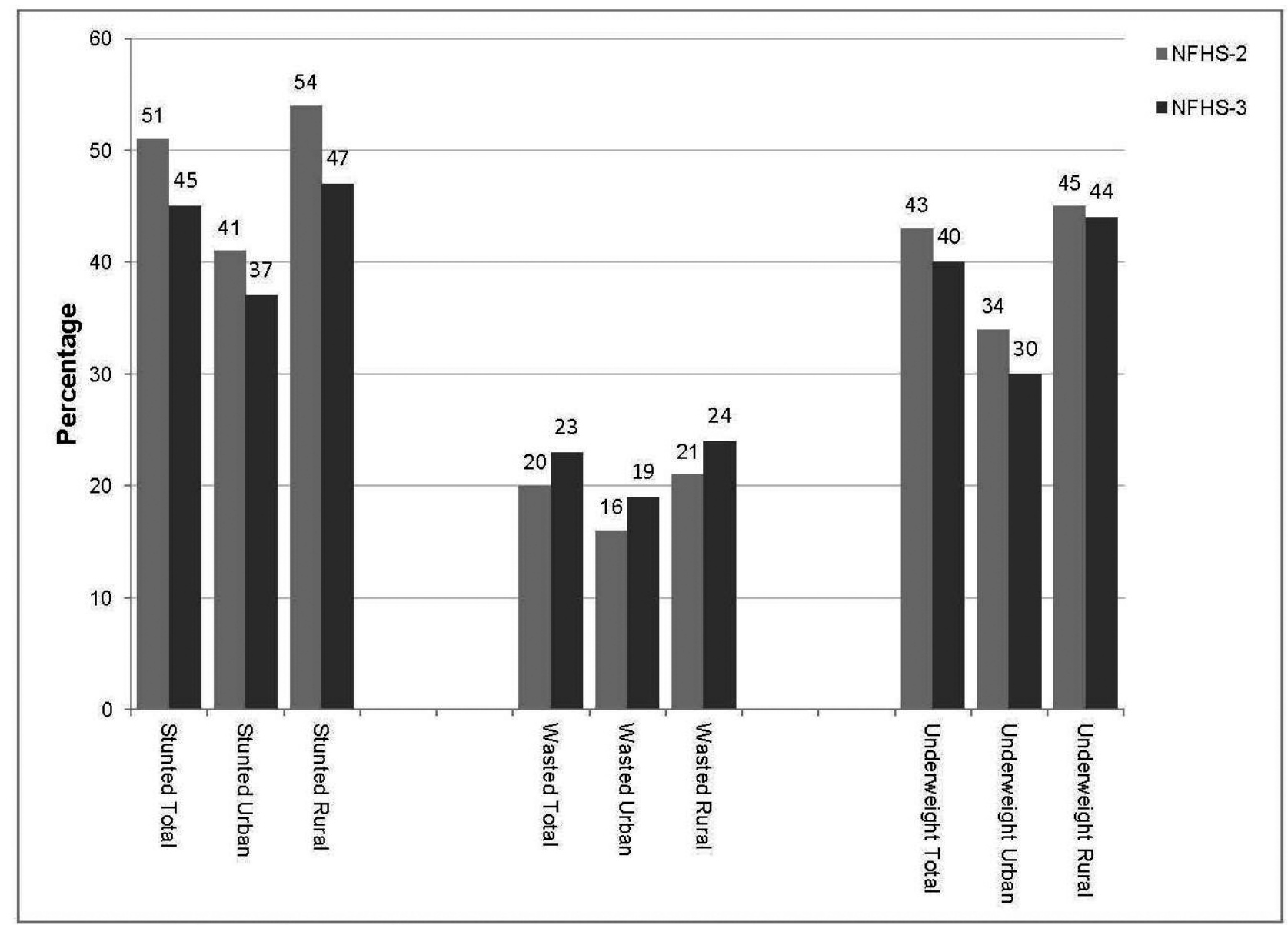

Source: Sachdev, Indian Paediatr 2012; 49 271-5

Fig. 1: Comparison of nutritional indices defined as per the WHO growth reference between 1998-99 and 2005-6 from the National Family Health Surveys in children below three years age

pregnancy, delivery and early infancy to improve growth at 2 years.

\section{National Infant and Young Child Feeding Program}

Comprehensive national policies and programs are required to ensure adequate nutrition, growth and development of infants, adolescents and pregnant women.

Such policies e.g., Guidelines for Enhancing Optimal Infant and Young Child Feeding Practices (Government of India, 2013) and programs like Integrated Child Development Services (http://icdswcd.nic.in/issnip/home.htm) have led to a decline in severe malnutrition, and severe micronutrient deficiency, but moderate grades of under-nutrition and specific nutrient deficiencies are still widely prevalent in India.
Further improvements will require action on many facets - legislation, policy, equitable development, minimum assured wages and employment, protection of rights of women, strengthening of health systems and health services, policy and programs on nutrient fortification of relevant foods (salt, milk, and cereals), animal husbandry, home gardens and special micronutrient supplementation programs. Programs will need to be organized in a way so that high coverage is achieved, support is provided by skilled health and nutrition workers and efforts at rehabilitation are embedded within a program for prevention of under-nutrition. Additionally, breast and complementary feeding promotion must be linked to measures that prevent infection, safe water, sanitation, excreta disposal, hygiene and to timely recognition and treatment of sick children close to home, with early and adequate referral. 
Countries have required a mix of counselling, supplementation, fortification, incentivisation of caregivers and workers, products of quality food and ways to make them accessible to achieve accelerated progress. Promotion of essential newborn care for institutional births and home visitation by ASHA workers has, and will further improve timeliness and exclusiveness of breast-feeding for the initial 6 months of life. Kangaroo Mother Care for LBW infants is closely linked to effective breast-feeding and must be promoted. Comprehensive policy reforms, strategies and delivery services with quality and equity are the only ways to accelerate the progress. Specific action must be embedded in a policy of equitable development so that there is a shift of lower social and economic groups to the middle level.

The critical window for complementary feeding is 6 to 24 months, and therefore community and home workers are critical in addition to anganwadi (ICDS)based support and supplementation.

India is also making a determined effort to promote water, sanitation and hygiene practices. The

\section{References}

Akobeng A K, Ramanan A V, Buchan I and Heller R F (2006) Effect of breast-feeding on risk of coeliac disease: a systematic review and meta-analysis of observational studies Arch Dis Child 91 39-43

Amitay E L and Keinan-Boker L (2015) Breast-feeding and childhood leukaemia incidence: a meta-analysis and systematic review JAMA Paediatr 169 e151025

Aune D, Norat T, Romundstad P and Vatten L J (2014) Breastfeeding and the maternal risk of type 2 diabetes: a systematic review and dose-response meta-analysis of cohort studies Nutr Metab Cardiovasc Dis 24 107-115

Bentley A, Das S, Alcock G, More N S, Pantvaidya S and Osrin D (2015) Malnutrition and infant and young child feeding in informal settlements in Mumbai, India: findings from a census Food Sc Nutr 3 257-271

Bloomfield S F, Exner M, Carlo Signorelli C, Nath K J and Scott E A (2012) The chain of infection transmission in the home and everyday life settings, and the role of hygiene in reducing the risk of infection International Scientific Forum on Home Hygiene

Bowatte G, Tham R, Allen K J, Tan D J, Lau M, Dai X and Lodge C J (2015) Breast-feeding and childhood acute otitis media: establishment of toilets in home was shown to reduce pathogen transmission and excreta disposal and hygiene behaviours are being additionally emphasized (Bloomfield et al., 2012). Nutrition programs have to integrate interventions that address dietary and non dietary issues with quality and equity. Maternal education and income are important. A small proportion of children, who develop SAM need rehabilitation and sustenance, thereafter.

\section{Acknowledgements}

We are thankful to Indian Paediatrics for permitting us to reproduce Figure 1, originally published in the article "Overcoming challenges to accelerating linear growth in Indian Children" by HPS Sachdev; Indian Pediatrics 2012; 49: 271-5. We acknowledge the core support provided by the Department of Maternal, Newborn, Child and Adolescent Health, WHO, Geneva; and the Centre for Intervention Science in Maternal and Child Health (RCN Project No. 223269), Centre for International Health, University of Bergen (Norway).

a systematic review and meta-analysis Acta Paediatr Suppl 104 85-95

Chowdhury R, Sinha B, Sankar M J, Taneja S, Bhandari N, Rollins N, Bahl R and Martines J (2015) Breast-feeding and Maternal Health Outcomes: A Systematic Review and Meta-Analysis Acta Paediatrica 104 96-113

Clemens J D, Stanton B, Stoll B, Shahid N S, Banu H and Chowdhury A K (1986) Breast-feeding as a determinant of severity in shigellosis. Evidence for protection throughout the first three years of life in Bangladeshi children Am J Epidemiol 123 710-720

Debes A K, Kohli A, Walker N, Edmond K and Mullany L C (2013) Time to initiation of breast-feeding and neonatal mortality and morbidity: a systematic review BMC Public Health 13 S 19

Dewey K G and Vitta B S (2013) Strategies for ensuring adequate nutrient intake for infants and young children during the period of complementary feeding Alive \& Thrive Technical Brief 7

Dias CC and Figueiredo B (2015) Breast-feeding and depression: a systematic review of the literature $J$ Affect Disord 171 142-154

Georgieff M K (2007) Nutrition and the developing brain: nutrient priorities and measurement Am J Clin Nutr 85 614S-620S 
Goldman A S (2007) The immune system in human milk and developing infant Breast feed Med 4 195-204

Government of India, Ministry of Health and Family Welfare (2011) Operational guidelines on facility based management of children with severe acute malnutrition New Delhi, Government of India

Government of India, Ministry of Health and Family Welfare (2013) Enhancing-optimal-IYCF-practices

Government of India, Ministry of Women and Child Development (2015) Rapid Survey on Children (2013-2014) India Fact Sheet

Hajeebhoy N, Nguyen P H, Mannava P, Nguyen T T and Mai L $\mathrm{T}$ (2014) Suboptimal breast-feeding practices are associated with infant illness in Vietnam Int Breast feed J 912

Horta B L and Victora C G (2013) Short-term effects of breastfeeding: A systematic review of the benefits of breastfeeding on diarrhoea and pneumonia mortality Geneva: World Health Organization

Horta B L, Loret de Mola C and Victora C G (2015a) Long-term consequences of breast-feeding on cholesterol, obesity, systolic blood pressure, and type-2 diabetes: systematic review and meta-analysis Acta Paediatr 104 30-37

Horta B L, Loret de Mola C and Victora C G (2015b) Breastfeeding and intelligence: systematic review and metaanalysis Acta Paediatr 104 14-19

International Institute for Population Sciences and Macro International (2007) National Family Health Survey (NFHS-3), 2005-06: India: Volume I Mumbai: International Institute for Population Sciences

International Institute for Population Sciences (2016) NFHS 4 fact sheets for key indicators based on final data

Jantscher-Krenn E and Bode L (2012) Human milk oligosaccharides and their potential benefits for the breastfed neonate Minerva Paediatr 64 83-99

Klement E, Cohen R V, Boxman J, Joseph A and Reif S (2004) Breast-feeding and risk of inflammatory bowel disease: a systematic review with meta-analysis Am J Clin Nutr 80 1342-1352

Lawn J E, Cousens S and Zupan J; Lancet Neonatal Survival Steering Team (2005) 4 million neonatal deaths: When? Where? Why? Lancet 365 891-900

Lindsay B, Saha D, Sanogo D, Das S K, Omore R, Farag T H, Nasrin D, Li S, Panchalingam S, Levine M M, Kotloff K, Nataro J P, Magder L, Hungerford L, Faruque A S, Oundo J, Hossain M A, Adeyemi M and Stine O C (2015) Association between shigella infection and diarrhoea varies based on location and age of children Am J Trop Med Hyg 93 918-924
Linkages/AED Exclusive Breast-feeding (2002) The Only Water Source Young Infants Need. Frequently Asked Questions (FAQ) Sheet 5 Washington DC, Academy for Educational Development

Lodge C J, Tan D J, Lau M X, Dai X, Tham R, Lowe A J, Bowatte G, Allen K J and Dharmage S C (2015) Breastfeeding and asthma and allergies: a systematic review and meta-analysis Acta Paediatr 104 38-53

NEOVITA Study Group (2016) Timing of initiation, patterns of breast-feeding, and infant survival: prospective analysis of pooled data from three randomised trials Lancet Glob Health 4 e266-75

Olofin I, McDonald C M, Ezzati M, Flaxman S, Black R E, Fawzi W W, Caulfield LE and Danaei G; Nutrition Impact Model Study (anthropometry cohort pooling) (2013) Associations of suboptimal growth with all-cause and cause-specific mortality in children under five years: a pooled analysis of ten prospective studies PLoS One $\mathbf{8}$ e64636

Pereira N M, Verma R J and Kabra N S (2015) Postnatal lactational counselling and neonatal weight pattern Indian Paediatr 52 579-582

Sachdev H P, Krishna J, Puri R K, Satyanarayana L and Kumar S (1991) Water supplementation in exclusively breast-fed infants during summer in the tropics Lancet 337 929-933

Sachdev H P (2012) Overcoming challenges to accelerating linear growth in Indian children Indian Paediatr 49 271-5

Sadauskaite-Kuehne V, Ludvigsson J, Padaiga Z, Jasinskiene E and Samuelsson U (2004) Longer breast-feeding is an independent protective factor against development of type 1 diabetes mellitus in childhood Diabetes Metab Res Rev 20 150-157

Sankar M J, Sinha B, Chowdhury R, Bhandari N, Taneja S, Martines J and Bahl R (2015) Optimal breast-feeding practices and infant and child mortality: a systematic review and meta-analysis Acta Paediatr 104 3-13

Schoonees A, Lombard M, Musekiwa A, Nel E and Volmink J (2013) Ready-to-use therapeutic food for home-based treatment of severe acute malnutrition in children from six months to five years of age Cochrane Database Syst Rev 6 CD009000

Sinha B, Chowdhury R, Sankar M J, Martines J, Taneja S, Mazumder S, Rollins N, Bahl R and Bhandari N (2015) Interventions to improve breast-feeding outcomes: a systematic review and meta-analysis Acta Paediatr 104 114-34

Upadhyay R P, Rai S K and Anand K (2012) Community neonatal practices and its association with skilled birth attendance 
in rural Haryana, India Acta Paediatr 101 e535-539

Victora C G, Adair L, Fall C, Hallal P C, Martorell R, Richter L and Sachdev H S; Maternal and Child Undernutrition Study Group (2008) Maternal and child undernutrition: consequences for adult health and human capital Lancet $371340-357$

Victora C G, Bahl R, Barros A J, França G V, Horton S, Krasevec J, Murch S, Sankar M J, Walker N and Rollins N C; Lancet Breast-feeding Series Group (2016) Breast-feeding in the 21st century: Epidemiology, mechanisms, and lifelong effect Lancet 387 475-490

WHO/PAHO (2001) Guiding principles for complementary feeding of the breast-fed child Washington DC, Pan American Health Organization WHO (2002a) Nutrient adequacy of exclusive breast-feeding for the term infant during the first six months of life Butte NF, Lopez-Alarcon MG and Garza C. Geneva, World Health Organization

WHO (2002b) IMNCI Adaptation Guide- Part 3 Study Protocols. Protocol for Adapting the Feeding Recommendations. Geneva, World Health Organization

WHO (2005) Guiding principles for feeding non-breast-fed children 6-24 months of age Geneva, World Health Organization
WHO (2009) Infant and young child feeding: model chapter for textbooks for medical students and allied health professionals Geneva, World Health Organization

WHO (2010) Guidelines on HIV and infant feeding. Principles and recommendations for infant feeding in the context of HIV and a summary of evidence. Geneva, World Health Organization

WHO (2011a) Optimal feeding of LBW infants in low-and middleincome countries Geneva, World Health Organization WHO (2011b) Guideline: Use of multiple micronutrient powders for home fortification of foods consumed by infants and children 6-23 months of age. Geneva, World Health Organization

WHO/UNICEF/USAID (2008) Indicators for assessing infant and young child feeding practices - Part 1 Definitions Geneva, World Health Organization Young Child Nutrition Working Group: Formulation Subgroup (2009) Formulations for fortified complementary foods and supplements: review of successful products for improving the nutritional status of infants and young children Food Nutr Bull 30 S239-55. 